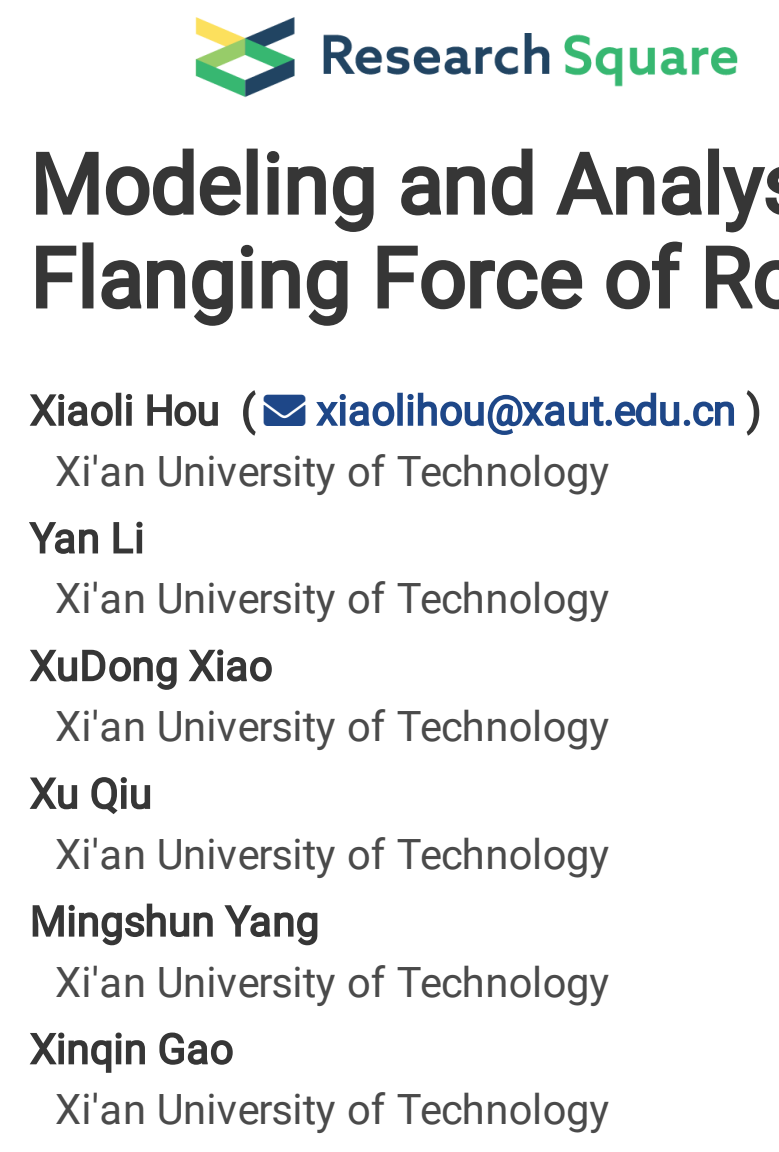

\author{
Xiaoli Hou ( $\nabla$ xiaolihou@xaut.edu.cn ) \\ Xi'an University of Technology \\ Yan Li \\ Xi'an University of Technology \\ XuDong Xiao \\ Xi'an University of Technology \\ Xu Qiu \\ Xi'an University of Technology \\ Mingshun Yang \\ Xi'an University of Technology \\ Xinqin Gao \\ Xi'an University of Technology
}

\title{
Modeling and Analysis of Multi-pass Progressive Flanging Force of Round Metal Tubes
}

\section{Research Article}

Keywords: incremental forming flanging, forming force, analytical model, experimental verification

Posted Date: November 9th, 2021

DOI: https://doi.org/10.21203/rs.3.rs-1029393/v1

License: (c) (i) This work is licensed under a Creative Commons Attribution 4.0 International License.

Read Full License 


\section{Modeling and analysis of multi-pass progressive flanging force of round}

\section{metal tubes}

Xiaoli Hou*1, Yan Li , Xudong Xiao, Xu Qiu, Mingshun Yang and Xinqin Gao

School of Mechanical and Precision Instrument Engineering, Xi'an University of Technology, No. 5 South Jinhua Road, Xi'an 710048, Shaanxi, China

Abstract: Pipe flanging is needed extensively in the industrial field, and its technological requirements are complicated and changeable. Currently the special flanging die and equipment are less flexible, while the whole set of equipment cost is high. As a result, pipe flanging technology with strong adaptability is necessary in single-piece or small-batch production. In this paper, a multi-pass progressive flanging process of round metal pipes with ball-end tool bar as forming tool is introduced, and dieless flanging of pipe can be realized by means of numerical control machine. In the dieless flanging process, the feedback and control of flanging force is a key factor for the flanging quality to meet design requirements. Therefore, this paper studies the change of flanging force in the multi-pass progressive flanging process of round metal tubes by combining theory, simulation and experiments. Based on the process of multi-pass progressive flanging of round pipes, an analytical model of the forming force of multi-pass progressive flanging of round pipes is established by taking the micro-element contacting tool bar with pipe as the research object. With the commercial ABAQUS finite element software, the multi-pass progressive flanging process of round pipes is simulated, and the evolution data of stress and strain field of the pipe during flanging process are obtained. Finally, a multi-pass progressive flanging test system is set up, and the three-dimensional forming force on the tool bar in flanging is measured. The flanging force measured by analytical calculation, finite element simulation and experiment is in good agreement. When the flanging angle is small, the radial forming force is the largest, followed by the axial forming force. As the flanging angle increases, the difference between radial forming force and axial forming force decreases gradually. When the flanging angle is greater than 30 to 40 degrees, the axial forming force becomes the largest, followed by the radial forming force.

Keywords: incremental forming flanging; forming force; analytical model; experimental verification

\section{Introduction}

Single Point Incremental Forming (SPIF) is a dieless forming technology for parts, which makes full use of the idea of "layered manufacturing". Its greatest advantage is that it does not need special dies, and has good flexibility. It can meet the market demand of personalized and diversified part manufacturing, attracting more and more attention from researchers.

Metal pipe parts have wide application prospects in numerous fields, including aerospace parts,

\footnotetext{
${ }^{1}$ Corresponding author: Email address: xiaolihou@xaut. edu. cn Phone: +86(029) 82312270
} 
automobile parts, medical devices ${ }^{[1]}$. Scholars at home and abroad have paid attention to and studied various pipe forming technologies, but few research have been made on the utility of progressive forming technology to realize the processing of thin-walled pipe parts.

Alves et al. ${ }^{[2]}$ adopted finite element numerical simulation and experimental methods to study the influence of technical parameters on plastic fracture, fold and local buckling of materials under the processing conditions of pipe end expansion, contraction, torsion and flanging, and conducted experiments with AA6060 aluminum alloy pipe. Teramae et al. ${ }^{[3]}$ used taper tools to produce hole flange for pipe branch applications. The finite element model and experiment are established to analyze the influence of strain hardening and anisotropy on the final tube wall thickness. Liu et al. ${ }^{[4]}$ studied the local stress-strain state in the deformation zone through membrane analysis. On the basis of membrane analysis, Cristino et al. ${ }^{[5]}$ established an incremental mechanical analysis model of tube expansion deformation, and explained the property mechanism of crack damage. Yang et al. ${ }^{[6]}$ conducted experimental and theoretical research on the process of tube coiling. Cao et al. ${ }^{[7]}$ conducted orifice flange experiment by developing a new flange tool and studied the stress relief and change by evaluating the thinning deformation with analytical method and numerical simulation.

Yang et al. ${ }^{[8]}$ extended incremental forming technology to the problem of producing dieless incremental hole flanges for thin-walled branch tubes. They conducted experiments and numerical simulations through the utilization of 316L stainless steel tubes, and discussed the estimation of pre-cut hole size and the process route planning. Finally, the force, deformation and defects in the process were summarized. Wen et al. ${ }^{[9]}$ restored the idea of using a single-point hemispherical tool to expand and contract the metal pipe end, and process the pipe wall groove and hole flange, thus studying the force, wall thickness and geometric shape under different process parameters. Wen et al. ${ }^{[10]}$ later replaced hemispherical tools with conical tools and extended incremental forming to the outer and inner flanging of pipe ends. Through experiments and numerical simulations, they identified the main problems caused by different process conditions and proved the overall feasibility of the process. F. RAHMANI et al. ${ }^{[1]}$ used incremental forming technology to process round tubes into square sections, and designed full factor experiments with spherical forming punches. They studied the influence of process parameters on the thinning rate and maximum outer diameter of square sections, and gave a regression model to predict the response.

Forming force is an important reason that affects the forming quality of metal tube end. Excessive forming force will lead to wrinkles on the surface of formed parts, and even cause cracks of formed parts. In order to solve this problem in the progressive forming process of metal pipes, this paper proposes a variable angle progressive tube end flanging forming process, aiming at reducing the forming force and improving the quality of products. An analysis model is presented that can explain the basic principle of tube end flanging in variable angle progressive forming. The force analysis model is based on the membrane analysis and the free body balance of local shell elements under the condition of rotational symmetry. The flanging 
process of $\mathrm{T} 2$ copper tube is simulated by finite element simulation software ABQUAS, and a test platform is constructed to complete the variable angle flanging experiment of $\mathrm{T} 2$ copper tube end. With the forming force as an observation index, we compare the results of experiment, simulation and theoretical calculation, and analyze the change of forming force and the influence of key technical parameters on the forming force. These steps are of theoretical and practical significance for flanging research of thin-walled metal pipes.

\section{Variable angle progressive flanging forming of metal tube}

\subsection{Forming principle}

The simulation process of flanging forming principle of metal pipe with variable angle is shown in Fig.1. The forming process is completed on a horizontal lathe, and the forming devices consist of a three-jaw chuck, a mandrel, a ball-head tool bar and forming parts. The mandrel is installed at one end of the metal tube to prevent the tube wall from being deformed due to the excessive clamping force of the three-jaw chuck when clamping one end of the metal tube. The spindle of the machine tool drives the tube material to rotate, and the ball-head tool bar is installed on the tool holder.

In the forming process, the tool holder controls the ball-head tool bar to move to the specified position according to the requirements of tube flanging height, and then processes the tube wall along the Z-direction (axial direction of the tube) spiral forming track. After the completion of axial feeding, the forming tool is retracted. Then the angle between the forming tool and metal tube wall is changed to carry out the second axial feeding. Finally, the variable angle flanging forming process is completed through multiple angle changes and axial feeding, and the flanging pipe fitting required by the process is obtained by cumulative forming. After the pre-forming process is completed, move the tool bar forward to the junction that the ballhead part can contacts the flanging area and the undeformed area, and then feed the tool bar along the $\mathrm{X}$ direction (radial direction of the pipe) to finish the straightening edge angle correction process of the round pipe. In Fig. $1, t_{0}$ and $t$ are the initial thickness and deformed thickness of the pipe, respectively; $V x, V z$ and $n$ are the radial feed speed, axial feed speed and spindle speed of the forming tool; $\alpha$ is the required rotation angle of the forming tool before each axial feed; $L$ is the initial total length of the metal pipe; $r$ and $R$ are the inner diameter and outer diameter of the round metal pipe, respectively.




Fig. 1 Principle of variable angle progressive flanging of metal pipe.

\subsection{Modeling of forming force}

In the process of metal tube flanging with variable angle, the contact unit between the ball-end tool bar and the metal tube wall is shown in the red contact area ABCD in Fig. 2. The micro-element method is adopted to study the forming force in all directions in the contact area between the forming tool and the metal tube. The tiny unit in the contact area $\mathrm{ABCD}$ is selected as the object of study, and then construct its cylindrical coordinates as shown in Fig.3. According to the force balance relationship in all directions, the forming force expressions in all directions are listed. Among them, $\sigma_{r}, \sigma_{\theta}$, and $\sigma_{L}$ are stress in the direction of vertical tube wall, tangential stress and stress in the direction of parallel tube wall, respectively. The forming forces corresponding to the three directions are expressed by $F_{r}, F_{\theta}$ and $F_{L}$, respectively: $t$ is the thickness of metal tube; $r$ is the inner diameter of metal tube; $d_{l}$ is the height of the contact micro-element; $d_{\theta}$ is the fan-shaped angle of the micro-element in the contact area; $\alpha$ is the angle between flanging area and Z-axis direction; $f$ is the friction coefficient between the forming tool and the tube wall ; and $\sigma_{s}$ is set as the yield limit of metal tube.

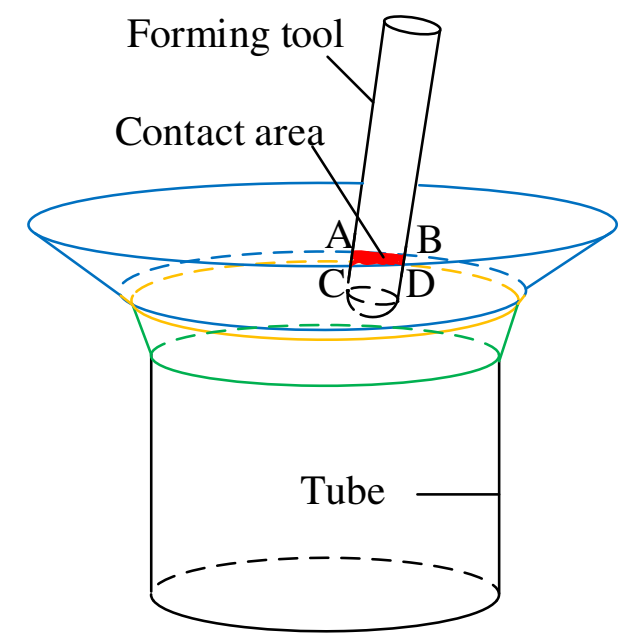

Fig. 2 Schematic diagram of variable angle flanging forming. 


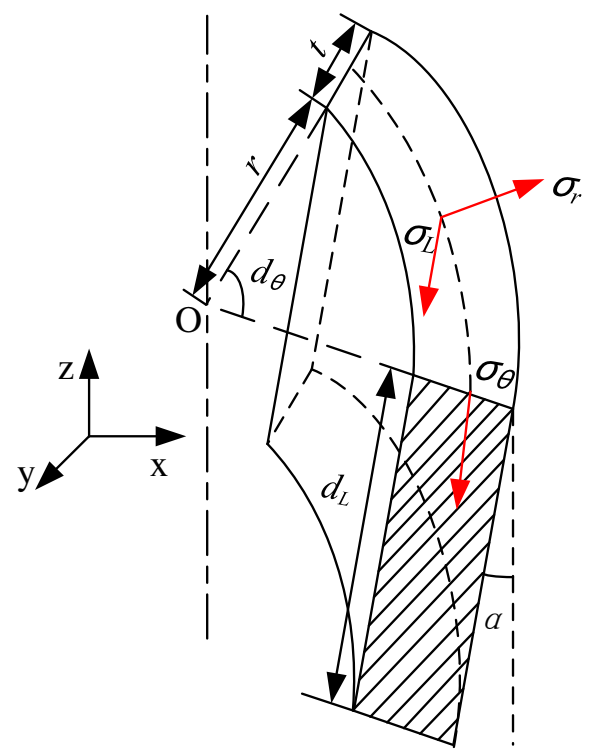

Fig. 3 Stress analysis of pipe micro-element.

The forming forces in three directions are:

$$
\begin{gathered}
F_{r}=r \cdot d_{\theta} \cdot d_{l} \cdot \sigma_{r} \\
F_{\theta}=t \cdot d_{l} \cdot \sigma_{\theta} \cdot \sin \frac{d_{\theta}}{2} \\
F_{L}=r \cdot d_{\theta} \cdot t \cdot \sigma_{L} \cdot \cos \alpha
\end{gathered}
$$

According to the geometric relationship in Fig. 3, the force balance in the direction perpendicular to the tube wall can be obtained as follows:

$$
\sigma_{r} \cdot r \cdot d_{\theta} \cdot d_{l}-2 \sigma_{\theta} \cdot \sin \frac{d_{\theta}}{2} \cdot t \cdot d_{l} \cdot \cos \alpha=0
$$

The force balance in the direction parallel to the die surface is:

$$
2 \sigma_{\theta} \cdot \sin \frac{d_{\theta}}{2} \cdot t \cdot d_{l} \cdot \sin \alpha+f \cdot \sigma_{r} \cdot r \cdot d_{\theta} \cdot d_{l}-\sigma_{L} \cdot r \cdot d_{\theta} \cdot t=0
$$

We take $\sin \frac{d \theta}{2}=\frac{d \theta}{2}, d_{l}=d_{r} / \sin \alpha$, and the equation can be simplified as:

$$
r \cdot \frac{d_{r}}{\sin \alpha} \cdot d_{\theta} \cdot \sigma_{r} \cdot f+2 \sigma_{\theta} \cdot \frac{d \theta}{2} \cdot t \cdot d_{r}-\sigma_{L} \cdot r \cdot d_{\theta} \cdot t=0
$$

Divide both sides of Eq. (6) by $d_{\theta}$, and we get

$$
r \cdot \frac{d r}{\sin \alpha} \cdot \sigma_{r} \cdot f+\sigma_{\theta} \cdot t \cdot d_{r}-\sigma_{L} \cdot r \cdot t=0
$$


If $\sigma_{1}=\sigma_{\theta}, \sigma_{2}=-\sigma_{r}, \sigma_{3}=-\sigma_{L}$, we obtain the following results according to Mises yield criterion.

$$
\begin{gathered}
\sigma_{1}-\sigma_{3}=1.15 \sigma_{s} \\
\sigma_{\theta}=1.15 \sigma_{s}-\sigma_{L}
\end{gathered}
$$

Then, we have

$$
\sigma_{r}=\frac{t}{r} \cdot \cos \alpha\left(1.15 \sigma_{s}-\sigma_{L}\right)
$$

Substituting Eqs. (9) and (10) into Eq. (7), we obtain

$$
\frac{d_{r} \cdot t \cdot f}{\sin \alpha} \cdot \cos \alpha \cdot\left(1.15 \sigma_{\mathrm{s}}-\sigma_{L}\right)+\left(1.15 \sigma_{\mathrm{s}}-\sigma_{L}\right) \cdot t-\sigma_{L} \cdot r \cdot t=0
$$

After repeated simplification, we can get:

$$
\sigma_{L}=\frac{1.15 \sigma_{s} \cdot d_{r}(f+1)}{\left(r+f \cdot d_{r} \cdot \cot \alpha+d_{r}\right)}
$$

Substitute Eq. (12) into Eq. (9), and the tangential stress is:

$$
\sigma_{\theta}=1.15 \sigma_{s}-\frac{1.15 \sigma_{s} \cdot d_{r}(f+1)}{\left(r+f \cdot d_{r} \cdot \cot \alpha+d_{r}\right)}
$$

According to the above, the radial force perpendicular to the tube wall in the deformation area is as follows:

$$
\sigma_{r}=\frac{1.15 \sigma_{s} \cdot t \cdot \cos \alpha}{r}-\frac{1.15 \cdot \sigma_{s} \cdot t \cdot \cos \alpha \cdot d_{r}(f+1)}{\left(r^{2}+f \cdot d_{r} \cdot r \cdot \cot \alpha+r \cdot d_{r}\right)}
$$

The stresses in three directions of Eqs. (12), (13) and (14) are transformed into stresses in three directions in the rectangular coordinate system.

$$
\left\{\begin{array}{l}
\sigma_{x}=\sigma_{r} \cdot \cos \alpha+\sigma_{L} \cdot \sin \alpha \\
\sigma_{y}=\sigma_{\theta} \\
\sigma_{z}=\sigma_{L} \cdot \cos \alpha+\sigma_{r} \cdot \sin \alpha
\end{array}\right.
$$

The forming forces in three directions are:

$$
\left\{\begin{array}{l}
F_{x}=F_{r} \cdot \cos \alpha+F_{L} \cdot \sin \alpha \\
F_{y}=F_{\theta} \\
F_{z}=F_{L} \cdot \cos \alpha+F_{r} \cdot \sin \alpha
\end{array}\right.
$$

Through theoretical calculation of the micro-elements in contact area, the force situation in all directions and their expressions are obtained. It can be seen that the changes of radial force and axial force 
are related to thickness, flanging angle and radius of tube turning area, and the tangential force is connected to radius and flanging angle.

\section{Finite element modeling}

Based on commercial ABAQUS finite element software, structural mechanics system analysis of the flanging forming process is carried out. In order to create a geometric model, we keep the original relative motion relation in the forming process, and simplify some forming devices. The deformation of pipe wall is mainly the materials tensile and shear deformation, while the stress-strain curve of corresponding materials can be obtained by statics tensile test, which is in line with the deformation of pipe wall materials in the actual metal pipe progressive forming process. The mechanical properties of $\mathrm{T} 2$ copper pipes used in this paper are shown in Table 1, and the parameters of Johnson-Cook constitutive model are displayed in Table 2 $[12]$.

When the temperature effect is not considered, the basic form of Johnson-Cook model is:

$$
\sigma=\left(A+B \varepsilon^{n}\right)\left[1+C \ln \dot{\varepsilon}^{*}\right]
$$

Where $\sigma$ is the effective stress, $\varepsilon$ is the effective plastic strain, $\varepsilon^{*}$ is the normalized effective plastic strain rate (typically normalized to a strain rate of $1.0 \mathrm{~s}^{-1}$ ), $n$ is the work hardening exponent, and $A, B \& C$ are constants.

Table 1 Material parameters

\begin{tabular}{lcccc}
\hline Material & $\begin{array}{c}\text { Density } \\
\left(\mathrm{g} / \mathrm{mm}^{3}\right)\end{array}$ & $\begin{array}{c}\text { Elastic modulus } \\
E(\mathrm{Gpa})\end{array}$ & $\begin{array}{c}\text { Poisson ratio } \\
v\end{array}$ & $\begin{array}{c}\text { Tensile strength } \sigma \mathrm{b} \\
(\mathrm{MPa})\end{array}$ \\
\hline Description & $8.9 \times 10^{-3}$ & 107.9 & 0.33 & 318 \\
\hline
\end{tabular}

Table 2 Parameters of J-C constitutive equation

\begin{tabular}{cccc}
\hline$A / \mathrm{Mpa}$ & $B / \mathrm{Mpa}$ & $n$ & $C$ \\
\hline 90 & 292 & 0.31 & 0.025 \\
\hline
\end{tabular}

The geometric model of the metal tube progressive flanging device includes the forming tool ball-head rod and tube material. By applying appropriate boundary conditions, the relative movement of the metal tube progressive forming is guaranteed. The red copper pipe used for the test has an initial inner diameter $r$ of $\varphi$ $67 \mathrm{~mm}$, a total length $L$ of $50 \mathrm{~mm}$ and a thickness $t_{0}$ of $1 \mathrm{~mm}$. According to this condition, the evolution law of stress and strain in the process of progressive flanging was simulated, and S4R shell element was selected to divide the pipe. The Coulomb friction is selected in accordance with the characteristics of the formed tube wall and lubrication conditions. The friction coefficient is set to be 0.1 and the boundary conditions are set by fixing one end and making similar displacement/rotation of the other end. Thus, the finite element geometric model of metal tube flanging as shown in Fig. 4 is established. The simulation process is divided 
into 6 steps. The increment of the oblique angle of forming tool is $10^{\circ}$ each step. The displacement distance in $z$ direction of the forming tool is $10 \mathrm{~mm}$. The forming tool rotates around the center axis of tube with rotating speed of $5 \pi \mathrm{rad} / \mathrm{s}$.

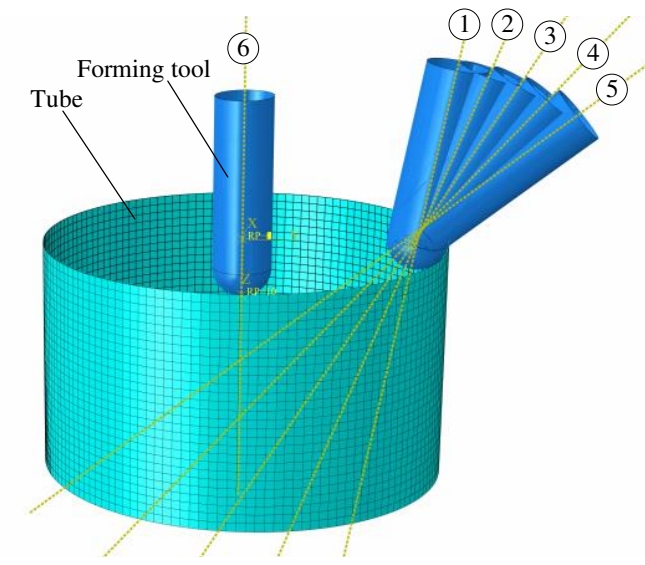

Fig. 4 Simulation model of multi-pass SPIF of metal tube.

\section{Test equipment and parameters}

According to the above theoretical analysis, in the process of variable angle flanging forming of metal pipe end, an excessive rotating speed of spindle will lead to diameter expansion, while too low a rotating speed makes the deformation of pipe wall material uneven. Each decrease of the flanging angle and axial feed velocity could reduce the equivalent stress in the pipe flanging process, exerting a positive effect on the processing. The decrease of the diameter of the forming tool (ball-end rod) will reduce the contact area between the tool and the metal pipe, resulting in a larger equivalent stress value and metal chips of different sizes, so tools with too small a diameter should be avoided. Therefore, considering the influence of parameters on the forming process, a forming force testing system based on KISTLER is established, and the changing rules of radial force and axial force are obtained through experiments. Compared with the simulation results, it is found that the forming force and the changing trend are in good agreement, which verifies the correctness and effectiveness of theoretical analysis. The technical parameters for testing and simulation are shown in Table 3. In the first five passes of the test, each flanging is preformed with an angle increment of $10^{\circ}$ until it is $50^{\circ}$, and the ball-end rod is restored to $0^{\circ}$ and directly pass the radial feed once so that the sizing flanging is completed.

$$
\begin{aligned}
& \text { Table } 3 \text { Test and simulation forming process parameters } \\
& \begin{array}{cccc}
\hline H(\mathrm{~mm}) & \alpha\left(^{\circ}\right) & n(\mathrm{rad} / \mathrm{s}) & V z(\mathrm{~mm} / \mathrm{r}) \\
\hline 10 & 10 & 5 \pi & 0.1 \\
\hline
\end{array}
\end{aligned}
$$

As shown in Fig. 5, a horizontal lathe is adopted as test platform. The three-jaw chuck is matched with the mandrel to clamp the pipe material, and the ball-end rod clamp is connected with the dynamometer. The force collected by the KISTLER 9257B three-way force sensor is transmitted to the charge amplifier which sends it to the data acquisition instrument, and then is read by the VIB'SYS software on the terminal computer. 
T2 copper, commonly used in industrial pipe fittings, is used as test pipe material. Synthesized by adding trace elements to pure copper, it has strong corrosion resistance and excellent plastic formability. The main chemical components of T2 are shown in Table 4. Ground from X210Cr W12 tungsten high speed steel, the tool head has high toughness, rigidity and wear resistance, making it hard to deform in the forming process. Kunlun L-HM46 antiwear hydraulic oil is chosen as lubricating oil.

Table 4 Chemical composition of $\mathrm{T} 2$ copper tube (\%)

\begin{tabular}{cccccccc}
\hline Trademark & $\mathrm{Cu}+\mathrm{Ag}$ & $\mathrm{Fe}$ & $\mathrm{Pb}$ & $\mathrm{Sb}$ & $\mathrm{As}$ & $\mathrm{S}$ & $\mathrm{Bi}$ \\
\hline $\mathrm{T} 2$ & 99.96 & 0.005 & 0.005 & 0.002 & 0.002 & 0.005 & 0.001 \\
\hline
\end{tabular}

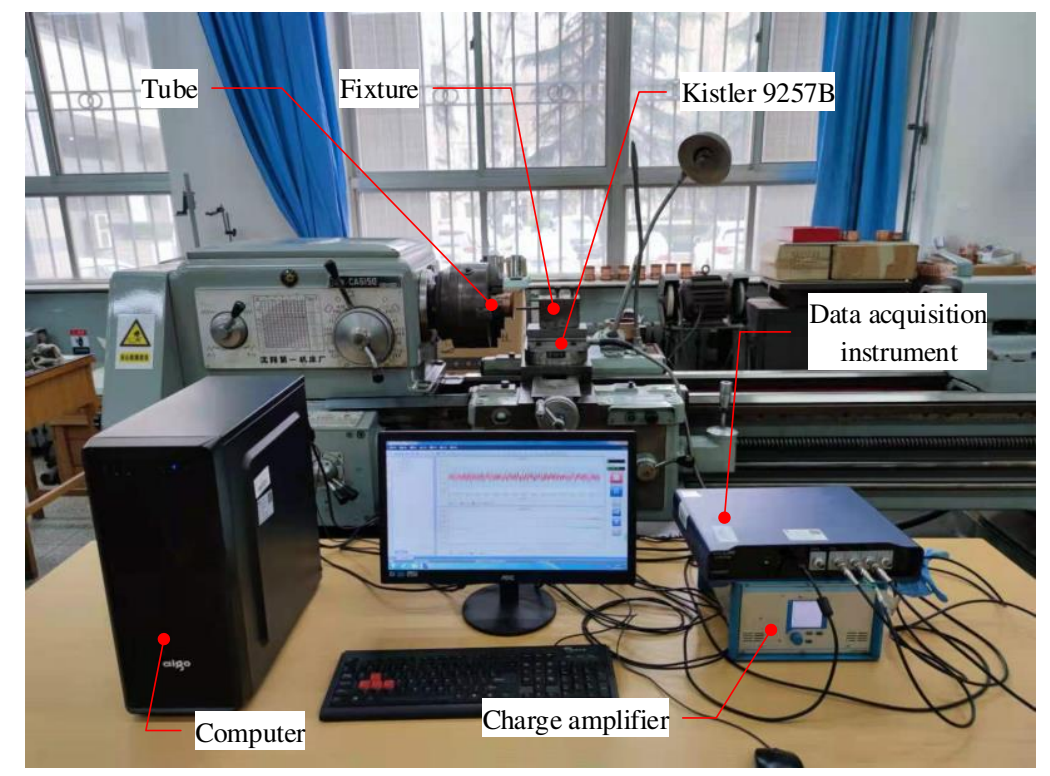

Fig. 5 Flanging forming test device.

\section{Results and discussion}

5.1 Finite element simulation results

According to the four key parameters of the process (spindle speed, flanging angle each time, axial feed speed and diameter of forming tool ball head), we designed a test scheme and carried out a finite element simulation. The results show that with different parameters, the changing trend of forming force in three directions is basically the same, and the influence laws of various influencing factors and their different levels on radial force and axial force are different. The radial force and axial force decrease with the increase of spindle speed, flanging angle and diameter of forming tool, and increase with the increase of axial feed speed. In terms of the parameters shown in Table 3, the finite element simulation is carried out to simulate the whole process of forming changing with time. The equivalent stress nephogram of six simulation passes is shown in Fig. 6. The forming force is derived to obtain a graph, as shown in Fig.7. 

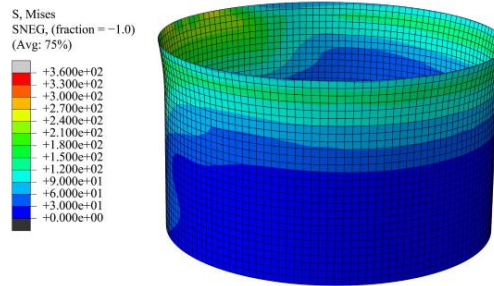

Step1

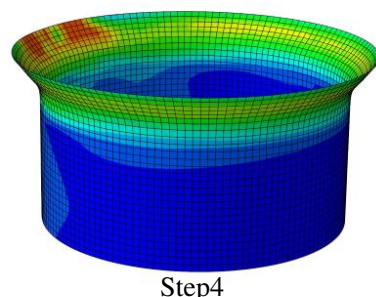

Step4

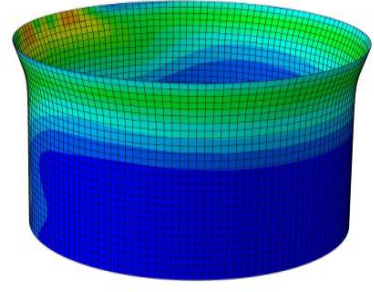

Step2

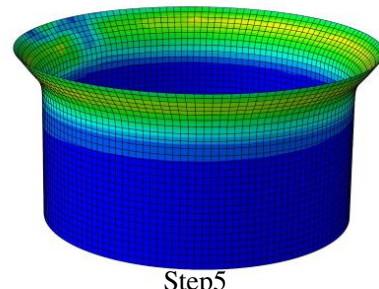

Step5

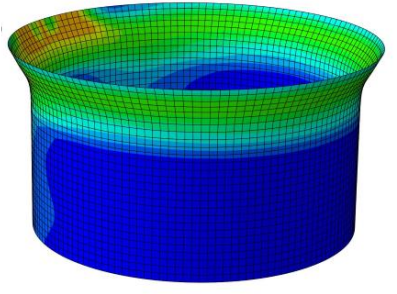

Step3

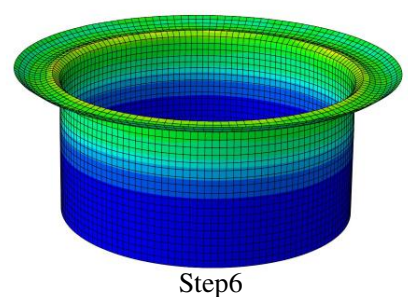

Fig. 6 Equivalent stress nephogram of 6 simulation passes.

According to Fig. 7, when the three-dimensional forming force is at $0^{\circ} \sim 40^{\circ}$, the peak value of each pass rises gradually with the growing of flanging angle. It is due to the fact that the pipe flanging area is in the elastic, yielding and strengthening stage of the plastic material deformation process, where the stress increases with flanging angle (i.e. strain) growing. When the tube flanging angle is about $40^{\circ}$, it reaches the strengthening stage and the forming force increases to the maximum of about $800 \mathrm{~N}$. When the flanging angle is greater than $40^{\circ}$, because of the continuous extrusion deformation, the plastic flow of the material enters the necking stage with the increase of flanging angle. Although the deformation continues to increase, the forming force tends to decrease gradually.

In each pass, the forming force increasing from zero to the peak value is a process in which the forming tool is axially fed from the pipe end. With the axial feeding distance getting larger, the forming force increases. The slow growth of forming force in the first half of axial feeding and the fast growth in the second half process are due to the fact that with the feeding distance growing, the deformation area of metal pipe is enlarged, thus the deformation increases. The closer the forming tool is to the undeformed area of pipe, the stronger the supporting effect of the forming tool is, which leads to the faster growth of forming force in the second half.

At the initial stage of forming, due to the small flanging angle, the forming tool directly participates in the extrusion deformation in the radial direction, while friction is the main force in the axial and tangential directions. Therefore, the radial force is the main forming force at $0^{\circ} \sim 40^{\circ}$. With flanging angle getting larger, the axial extrusion deformation of the metal pipe by the forming tool is gradually heavy, so the axial force transits into the main force. 


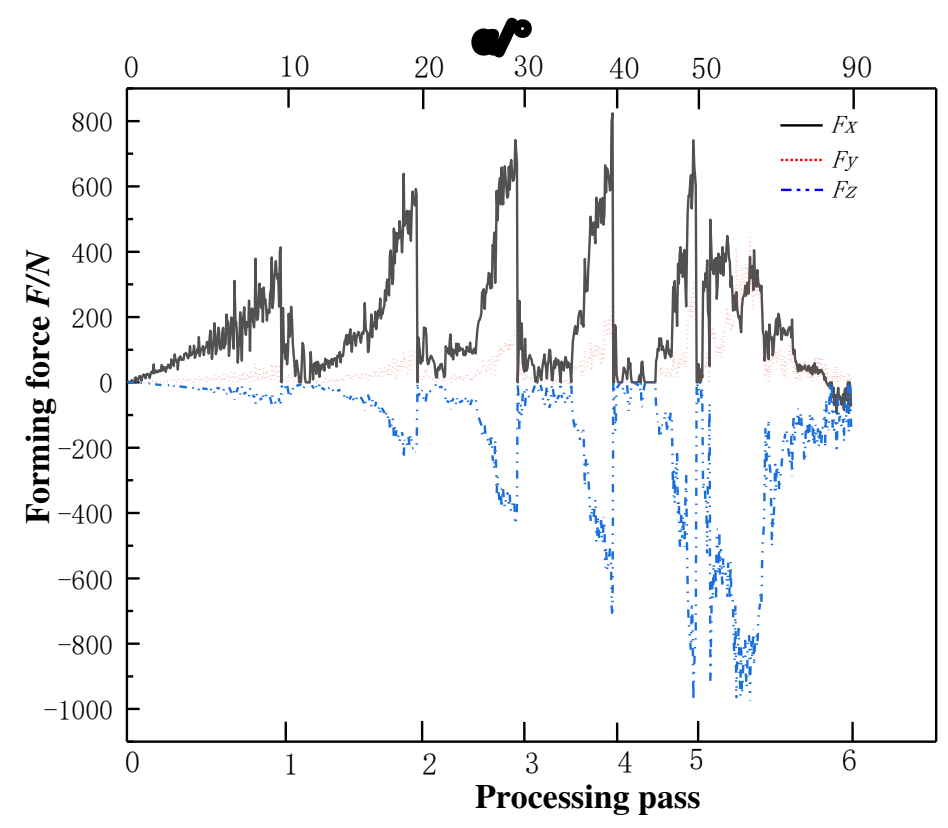

Fig. 7 Variation of simulated forming force.

\subsection{Test results and analysis}

For quantitative analysis and comparison, we still use the process parameters consistent with the finite element simulation in the experiment. The obtained flanging formed parts are shown in Fig. 8.



Fig. 8 Formed parts obtained from experiment.

Fig.9 shows the curve of the forming force data collected during the test. It can be seen that in each pass, the forming forces in three directions gradually climb from 0 to the peak value, and then decrease from the peak value to 0 . The peak values of the three-direction forces grow first and then decline. In the initial stage of pipe flanging, the radial force $F_{x}$, obviously greater than $F_{y}$ and $F_{z}$, is the main forming force. When the flanging angle reaches $30^{\circ}$, the peak value reaches the maximum and begins to decline. When the flanging angle reaches $40^{\circ}$, the axial force $F_{z}$ gradually exceeds $F_{x}$ to become the main forming force. The overall variation trend of the three-dimensional forming force obtained from the test is consistent with the finite element simulation results, that is, the radial force is the largest when the processing pass is at $0^{\circ} \sim 30^{\circ}$, and 
then at above $30^{\circ}$, the axial force exceeds the radial force to become the main forming force, which verifies the reliability of the finite element model.

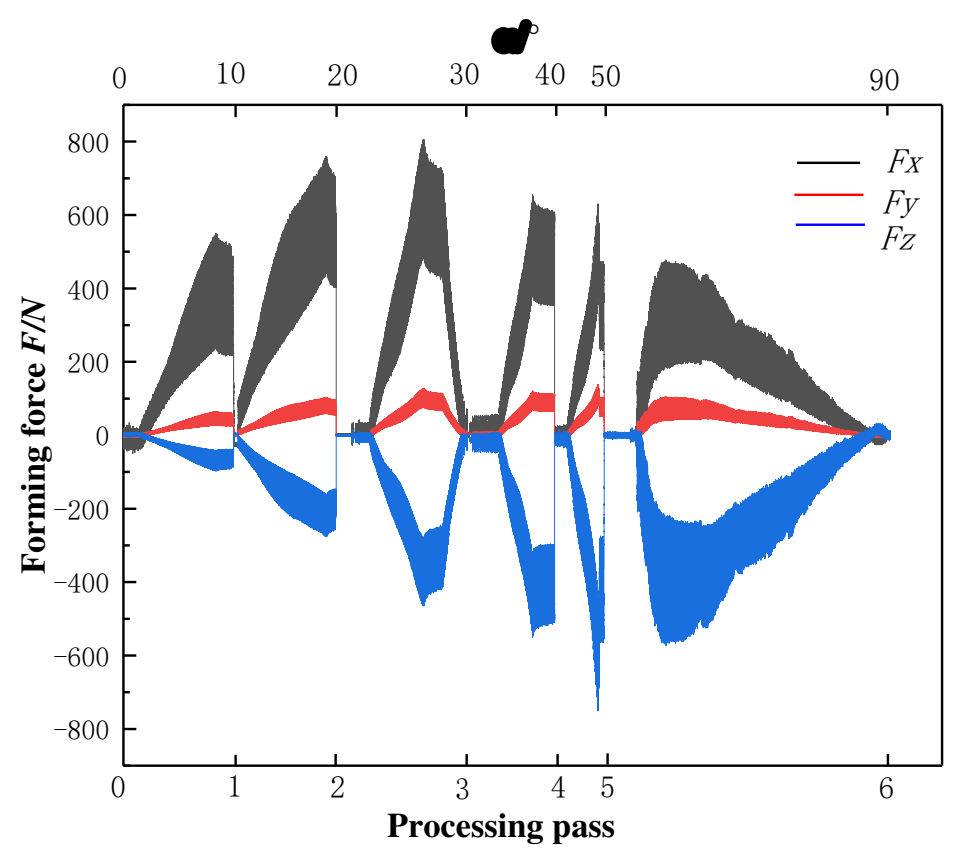

Fig. 9 Curve between three-dimensional forming force and machining pass.

Compared with the results of finite element simulation, there is a process that forming force gradually decreases from peak to 0 , because in the initial retreat stage of the forming tool, it is gradually separated from the metal pipe due to the rebound of the metal. Fig. 10 shows the change of forming force in the second pass.

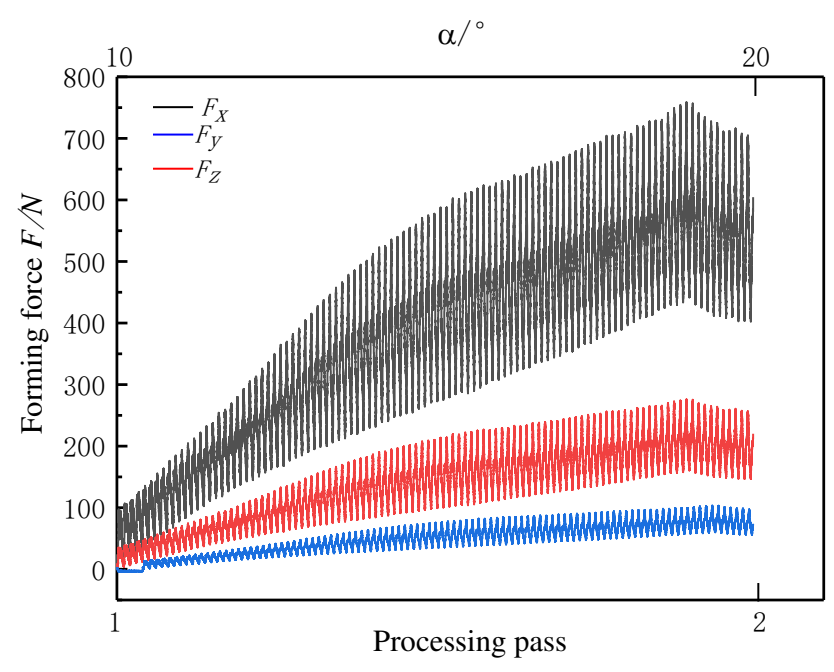

Fig. 10 Change of forming force in the second processing pass.

The radial force and axial force peak data obtained from test, simulation and theory - spindle speed $(5 \pi \mathrm{rad} / \mathrm{s})$, forming tool diameter $(10 \mathrm{~mm})$, each flanging angle $\left(10^{\circ}\right)$ and axial feed speed $(0.1 \mathrm{~mm} / \mathrm{r})-$ is derived and plotted in Fig. 11. It can be seen that the theoretical and simulation results tend to be in accordance with the test results, which verifies the correctness and effectiveness of the theoretical analytical 
model.

In the initial stage of flanging, the pipe flanging angle is small, and the friction between the forming tool and the metal pipe is the main force in the axial direction with no direct extrusion effect. However, the radial forming tool directly extrudes the metal pipe. With the increasing of deformation angle, the extrusion deformation gradually changed from radial action to axial action. Therefore, the radial force increases at first and then decreases, while the axial forming force continues to increase until the plastic deformation is completed, and then decreases in the process of straightening.



(a) Radial forming force

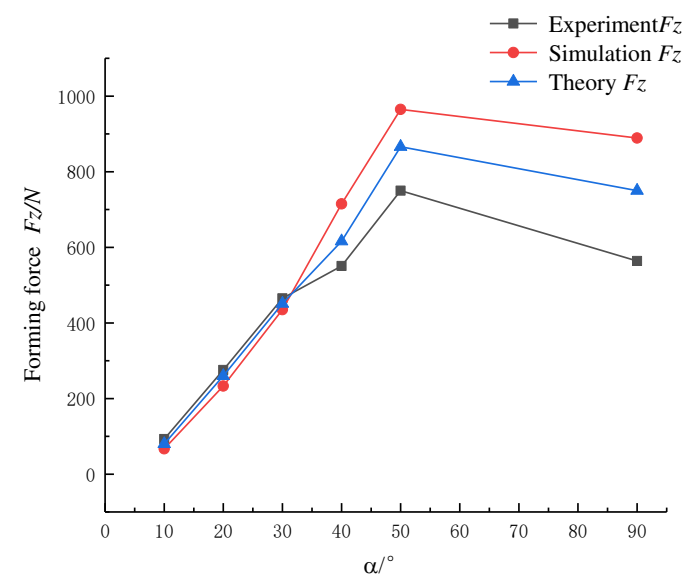

(b) Axial forming force

Fig. 11 Comparison of forming force.

Table 5 Comparison of average forming force results

\begin{tabular}{ccc}
\hline Parameters & $F_{x}$ & $F_{z}$ \\
\hline Average simulation forming force(N) & 642.8 & 565 \\
Average experimental forming & 669 & 475 \\
force(N) & & 503.83 \\
Average theoretical forming force(N) & 662.97 & 16.23 \\
Maximum error(\%) & 3.92 & \\
\hline
\end{tabular}

Table 6 Comparison of maximum forming force results

\begin{tabular}{ccc}
\hline Parameters & $F_{x}$ & $F_{z}$ \\
\hline force(N) & 823 & 946.12 \\
Experimental maximum forming & 792.09 & 768.81 \\
force(N) & & 866 \\
Theoretical maximum forming force & 827.64 &
\end{tabular}


Table 5 shows the comparison of average forming forces of simulation, experiment and theoretical calculation, and Table 6 shows the comparison of maximum forming forces of simulation, experiment and theoretical calculation. The axial forming force error is within $20 \%$, with the average being $16.23 \%$ and the maximum $18.74 \%$. The radial forming force error is the smallest, within $5 \%$, with the average being $3.92 \%$, and the maximum $4.30 \%$. The errors in the experimental, simulation and theoretical calculation results are mainly caused by two facts: on the one hand, the simplification of the fixture model in simulation ignores the vibration, hardening and other factors in forming; on the other hand, the approximate model is used instead of the actual model for the simulation, resulting in differences between the material parameter setting and the actual situation.

\section{Conclusion}

In this paper, a new multi-pass incremental flanging technology for metal pipe is presented. To study this technology in depth, this paper discusses the progressive flanging mechanism, and establishes an analytical model and finite element model. Through experiments, the validity of the above model is verified and the following conclusions are drawn:

(1) The principle of multi-pass progressive flanging of metal pipe is analyzed, and the analytical model representing micro-elements in the contact area of forming tool and metal pipe is established. It helps to obtain the expression of three-dimensional forming force, which reveals the internal relationship of the progressive flanging forming force of pipe and flanging process parameters, and material parameters.

(2) Through finite element simulation analysis, the variation law of forming force in three directions is verified. When the pipe flanging angle is at $0^{\circ} \sim 30^{\circ}$, radial force is the main forming force. When the flanging angle increases, the plastic flow direction of metal material gradually changes, making the axial force the main forming force. The tangential forming force is mainly caused by the tangential friction between the forming tool and the metal pipe. Being influenced by the pressure, roughness and lubricant, the force value is relatively small.

(3) This study constructs a multi-pass progressive flanging test platform for metal pipe, and measures the forming force data in the test. Analysis of the data obtained by analytical calculation, simulation and test indicates that the three trends are consistent. The comparative error between the radial forming force obtained by theory and simulation and by experiment is within $5 \%$, and that of the axial forming force is less than $20 \%$, which verifies the validity of analytical analysis model and the reliability of finite element simulation results.

(4) The radial and axial force in the forming process are related to the current flanging angle and the angle increment of each pass. The larger the angle increment in each pass is, the greater the pipe deformation and both radial and axial forces. When the flanging angle changes from $0^{\circ}$ to about $45^{\circ}$, the radial force on the forming tool gradually increases. When the flanging angle is getting larger, the radial force gradually 
decreases, with the main forming force changing from radial force to axial force.

Funding This work was financially supported by the National Natural Science Foundation of China (grant number 52075437 and 51805432).

Conflicts of interest/Competing interests: Not applicable.

Consent to participate: The authors participated in the study.

Consent for publication : The authors agree to publish.

Authors' contributions: Conceptualization: Xiaoli Hou; data curation: Xiaoli Hou; formal analysis: Yan Li; funding acquisition: Yan Li \& Xudong Xiao; project administration: Xu Qiu; resources: Xu Qiu; investigation: Minshun Yang; methodology: Xudong Xiao; writing—review\& editing: Xiaoli Hou; project administration: Xinqin Gao.

\section{References}

[1]Yang H, Li H, Zhang ZY, et al. Advances and trends on tube bending forming technologies[J].Chinese Journal of Aeronautics,2012,25,(1): 1-12.

[2]M.L. Alves, B.P.P. Almeida, P.A.R. Rosa, et al. End forming of thin-walled tubes [J]. Journal of Materials Processing Technology 177 (2006) 183-187.

[3]T. Teramae , K. Manabe, K. Ueno ,et al. Effect of material properties on deformation behavior in incremental tube-burring process using a bar tool[J]. Journal of Materials Processing Technology 191 (2007) 24-29.

[4]Liu Z B, Liu S, Li Y L, et al. Modeling and Optimization of Surface Roughness in Incremental Sheet Forming using a Multiobjective Function[J]. Materials and Manufacturing Processes, 2014, 29(7):808-818.

[5]Cristino V A, Magrinho J P, Centeno G, et al. Theory of single point incremental forming of tubes [J]. Journal of Materials Processing Technology, 2020:116659.

[6]Yang H, Li S P. Process optimization of the inverting-forming of thin-walled tubes with radiused dies [J]. Journal of Materials Processing Technology. 1995 , 52(2):489-495.

[7]Tingting Cao , Bin $\mathrm{Lu}$, Hengan $\mathrm{Ou}$, et al. Investigation on a new hole-flanging approach by incremental sheet forming through a featured tool[J]. International Journal of Machine Tools \& Manufacture 110 (2016) 1-17.

[8]C. Yang, T. Wen , L.T. Liu, et al. Dieless incremental hole-flanging of thin-walled tube for producing branched tubing [J]. Journal of Materials Processing Technology 214 (2014) 2461-2467.

[9]Wen, T., Yang, C., Zhang, S., Liu, L.T., 2015. Characterization of deformation behavior of thin-walled tubes during incremental forming: a study with selected examples [J]. Int. J. Adv. Manuf. Technol. 78, 1769-1780.

[10]Wen, T., Zheng, J., Qing, J., Fang, J., 2017. Outwards and inwards crimping of tube ends by single-point incremental forming [J]. Procedia Eng. 207, 854-859.

[11]F. RAHMANI, S. M. H. SEYEDKASHI, S. J. HASHEMI. Converting circular tubes into square cross-sectional parts using incremental forming process [J]. Trans. Nonferrous Met. Soc. China 29(2019) 2351-2361.

[12]Frank J, Zerilli, Ronald W. Armstrong. Dislocation-Mechanics-based constitutive relations for material dynamics 
calculations [J]. J. Appl. Phys.1987, 61(5), 1816-1825. 